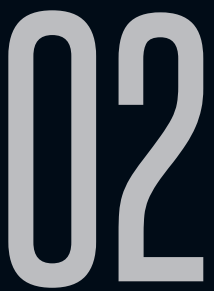

\title{
AUTORIA DE MULHERES NO CINEMA DE FICÇÃO CIENTÍFICA BRASILEIRO: OUTRAS PERSPECTIVAS PARA O FEMINISMO CONTEMPORÂNEO ${ }^{1}$
}

Carolina de Oliveira Silva (Mackenzie)

Recebido em 25 out 2019. Carolina de Oliveira Silva é Doutoranda em Aprovado em 23 mar 2020. Educação, Arte e História da Cultura pelo Mackenzie desde fevereiro de 2018 com a pesquisa "ELAS ESTÃO ENTRE NÓS! Corpos presentes, femininos ausentes no cinema de ficção científica brasileiro" sob orientação da Profa. Dra. Rosana Schwartz, Mestre em Comunicação pela Universidade Anhembi Morumbi (UAM), sob a orientação do Prof. Dr. Rogério Ferraraz, concluiu sua dissertação "Ausentes, Vingativas, Irreverentes, Infantis: as personagens femininas na obra de Quentin Tarantino" em setembro de 2017, é também Especialista em "História da Arte: Teoria e Crítica" pela Universidade Paulista de Artes, concluiu a graduação em "Comunicação Social Rádio, TV e Internet" pela UAM em 2014 com o mockumentary "Dormiu no Ponto" e é formada também em Fotografia e Design Gráfico. Possui experiência em televisão como estagiária nas áreas de Jornalismo, Produção Infantil e Departamento de Artes (Fundação Padre Anchieta), é editora de vídeo e atualmente trabalha como professora de Cinema, Rádio e TV no SENAC.

1 Artigo apresentado no II Colóquio Modos de hacer: cines y mujeres de América Latina na mesa Gêneros. O evento aconteceu nos dias 11, 12 e 13 de setembro de 2019 na Universidad Autônoma de Madrid. 
Resumo: Este artigo pretende desenvolver uma reflexão acerca da perspectiva de cineastas mulheres no cinema brasileiro a partir de um recorte que abarque a cinematografia de ficção científica nacional. Ao abordar o filme Kenoma (1998) de Eliane Caffé e Acquaria (2003) de Flávia Moraes, essa pesquisa pretende questionar: quais as contribuições do gênero para o desenvolvimento de um olhar feminino? Quais as perspectivas para uma FC brasileira em meio as prerrogativas do feminismo contemporâneo? Ao analisar os meios de representação para as personagens femininas, a utilização do corpo como um dos meios de contestação e as temáticas ambientais - a falta de água e o modo de vida primitivo - abordados no filme, a hipótese é de que, mesmo confirmando a escassez quanto a autoria, a própria FC científica brasileira resguarda aproximações muito contundentes com a história das mulheres no país, assim como, possui muito a dizer sobre uma alternativa cada vez mais decisiva em nossa forma de convívio social.

Palavras-chave: Cineastas Mulheres; Cinema Brasileiro; Ficção Científica; Teorias Feministas Contemporâneas.

Abstract: This article aims to develop a reflection on the perspective of female filmmakers in Brazilian cinema from a perspective that encompasses national science fiction cinematography. By approaching the film Kenoma (1998) by Eliane Caffé and Acquaria (2003) by Flávia Moraes, this research aims to question: what are the contributions of the genre to the development of a feminine look? What are the prospects for a Brazilian SF amid the prerogatives of contemporary feminism? In analyzing the means of representation for female characters, the use of the body as one of the means of contestation and the environmental themes - lack of water and the primitive way of life - addressed in the films, the hypothesis is that, even confirming the scarcity of authorship, the Brazilian 
scientific SF itself safeguards very strong approaches to the history of women in the country, as well as has much to say about an increasingly decisive alternative in our way of socializing.

Keywords: Women Filmmakers; Brazilian Cinema; Science Fiction; Contemporary Feminist Theories.

\section{INTRODUÇÃO}

O cinema brasileiro de autoria feminina é um terreno em constante desbravamento. Cada descoberta ainda se mostra como um pequeno tijolo solto em meio ao grande e estático muro da historiografia do nosso cinema. Como um tipo de arqueologia que pretende trazer à tona as diferentes trajetórias de opressão, invisibilidade e resistência feminina, o contexto oferecido pelas histórias de ficção científica, como bem aponta a escritora estadunidense Ursula K. Le Guin (2014) e da qual nos valemos aqui, não prevê o futuro, mas descreve o seu tempo e, em um movimento cada vez mais plural, buscamos contemplar outras histórias. Em 2018, o lançamento do livro Feminino Plural - Mulheres no cinema brasileiro, organizado por Karla Holanda e Marina Cavalcanti Tedesco preocupou-se em abranger diversos períodos da história e seus diferentes tons: o cinema silencioso e moderno, o cinema durante a ditadura militar, a militância feminista, o cinema das décadas de 1970-80, o cinema erótico, os protagonismos, o cinema negro, o documentário, os curtas-metragens, os documentários biográficos e, finalmente, as subversões.

Ao considerar diferentes linhas de pensamento, é como se a cada momento descobríssemos universos paralelos que não sabíamos, até então, que existiam. Dessa maneira, trazemos à moda 
da boa e velha FC, uma abordagem que pode e deve considerar uma história do cinema brasileiro de ficção científica contada por mulheres. Em um exemplo de longa-metragem, trazemos à tona os filmes Kenoma (1998) de Eliane Caffé e Acquaria (2003) de Flávia Moraes, todavia, a intenção, é claro, não é identificar forçosamente temáticas feministas em filmes que, a princípio, não se preocupariam com isso, e sim discorrer a partir de histórias que possam ser pensadas de uma perspectiva pouco considerada ou como a própria história das mulheres indica: invisibilizada por uma lógica amplamente positivista, linear a androcêntrica. Como bem apontam os autores Ella Shohat e Robert Stam (2006) em suas dedicadas análises multiculturalistas que abarcam toda e qualquer produção como um processo cultural de igual importância, as produções podem ser críticas e o mais importante, efetivamente colaborativas em todas as suas esferas.

O desafio reflexivo à representação, típico de filmes mais recentes como Reassemblage (1982), foi antecipado em Pouco a pouco (Petit à Petit, 1969). Nele, Jean Rouch faz seu protagonista africado Damoure "praticar antropologia" dentro da "estranha tribo" conhecida como parisienses, medindo seus crânios e os interrogando sobre seus costumes bizarros. Alguns filmes brasileiros dos anos 70, como Congo (1977), de Arthur Omar, ridicularizaram a própria ideia de que um cineasta branco fosse capaz de dizer qualquer coisa de valor sobre a cultura indígena ou africana no Brasil, enquanto outros, como os de Andrea Tonacci, simplesmente cediam a câmera para o "outro" a fim de possibilitar uma "conversa" de mão dupla entre os brasileiros urbanos e os grupos nativos. Às vezes o diálogo se voltava contra os próprios cineastas. Em Raoni (1978), os 
índios ponderam sobre a possibilidade de matar os cineastas - para eles, apenas outro grupo de assassinos em potencial - e decidem por fim poupálos para que "levem nossa mensagem ao homem branco". Em Mato eles? (1983), de Sérgio Bianchi, um índio pergunta ao diretor exatamente quanto dinheiro ele vai ganhar com o filme, tipo de pergunta inconveniente que em geral acabaria no lixo da sala de edição. Assim, o cineasta assume alguns riscos de um diálogo real, de um desafio potencial da parte de seus interlocutores. A questão não é mais como representar o outro, mas como colaborar com o outro em um espaço em comum. O objetivo, raramente é alcançado, é garantir a participação efetiva do "outro" em todas as fases da produção. (2006, p.69)

Assim, ao insistirmos na participação e na diversidade, justificamos, enfim, o recorte proposto para esta análise: partimos de 36 filmes elegidos para compor uma visão que considere, num primeiro momento, a relevância do corpo feminino nas histórias de FC no cinema brasileiro. Entretanto, as questões de autoria feminina voltam ao que Shohat e Stam (2006) nomeiam como todas as fases da produção, afinal, ao considerarmos um filme como um documento efetivo da história, e não apenas da história apresentada no roteiro, as circunstâncias de produção também pretendem dizer muito sobre a nossa própria história.

Os 36 filmes foram elegidos a partir da leitura da tese de doutorado de Alfredo Luis Paes Suppia (2007) intitulada Limite de Alerta! Ficção Científica em Atmosfera Rarefeita: Uma introdução ao estudo da FC no cinema brasileiro e em algumas cinematografias off-Hollywood. Com o intuito de abranger ao máximo as diferentes histórias que engendram a FC brasileira - comédia, terror, pornochanchada, 
musicais, filmes experimentais e outros, a escolha dos filmes não obedece a uma lógica que trata de temáticas feministas, mas sim de demonstrar as mais distintas abordagens dessas personagens, misturando protagonistas, não protagonistas e antagonistas.

\section{AS MULHERES DA FC BRASILEIRA}

Ao nos voltarmos para a cinematografia brasileira de ficção científica e de autoria feminina com destaque para a produção de longas-metragens, o cenário é tão escasso e incerto quanto a própria produção nacional do gênero. O recorte que destaca a autoria feminina no cinema desse gênero, na verdade, é fruto de um questionamento que pretende compreender como é feita a construção do corpo feminino nesses filmes. Assim, ao me deparar com 362 títulos produzidos entre os anos de 1947 e 2016, a lista que parecia extensa tornou-se pequena quando a pergunta sobre a autoria feminina foi efetivamente lançada.

Dos 36 filmes, apenas dois títulos, Kenoma e Acquaria foram dirigidos por mulheres: Eliane Caffé e Flávia Moraes. Ambas as produções carregam o nome de cidades em suas histórias, colocando quase sempre em pauta as questões de convivência das relações entre os humanos e o meio em que se vive, ou seja, o coletivo. No que se refere à produção e aos elencos, a participação das mulheres também está longe da equidade, como mostra a tabela abaixo, elaborada a partir das informações cadastradas sobre a filmografia brasileira na base de dados da Cinemateca ${ }^{3}$.

2 Os 36 filmes citados fazem parte de minha tese de doutorado "Elas estão entre nós! Corpos presentes, femininos ausentes no cinema de ficção científica brasileiro".

3 Em algumas produções as informações não se encontravam disponíveis na base de dados da cinemateca, nessas situações, utilizou-se como fonte o site IMDB. 


\begin{tabular}{|c|c|c|}
\hline Filme & $\begin{array}{l}\text { Mulheres/ } \\
\text { homens no } \\
\text { elenco }\end{array}$ & $\begin{array}{l}\text { Mulheres/ } \\
\text { homens na } \\
\text { produção }\end{array}$ \\
\hline $\begin{array}{c}\text { Uma Aventura aos } 40 \text { (1947) } \\
\text { de Silveira Sampaio }\end{array}$ & $2 / 2$ & $0 / 4$ \\
\hline $\begin{array}{c}\text { O Homem do Sputnik (1959) } \\
\text { de Carlos Manga }\end{array}$ & $7 / 21$ & $2 / 17$ \\
\hline $\begin{array}{c}\text { Os Cosmonautas (1962) de } \\
\text { Victor Lima }\end{array}$ & $2 / 8$ & $1 / 20$ \\
\hline $\begin{array}{c}\text { O 5o Poder (1962) de Alberto } \\
\text { Pieralisi }\end{array}$ & $2 / 20$ & $2 * / 22$ \\
\hline $\begin{array}{c}\text { A Espiã Que Entrou em Fria } \\
\text { (1967) de Sanin Cherques }\end{array}$ & $11 / 23$ & $0 / 20$ \\
\hline $\begin{array}{c}\text { Roberto Carlos em Ritmo de } \\
\text { Aventura (1968) de Roberto } \\
\text { Farias }\end{array}$ & $6 / 11+$ & $0 / 6$ \\
\hline $\begin{array}{l}\text { O Homem Que Comprou o } \\
\text { Mundo (1968) de Eduardo } \\
\text { Coutinho }\end{array}$ & $5 / 25$ & $2 / 11$ \\
\hline $\begin{array}{l}\text { Brasil Ano } 2000 \text { (1969) de } \\
\text { Walter Lima Jr. }\end{array}$ & $3 / 10$ & $0 / 14$ \\
\hline $\begin{array}{l}\text { O Jardim das Espumas (1970) } \\
\text { de Luiz Rosemberg Filho }\end{array}$ & $2 / 8$ & $3 / 7$ \\
\hline $\begin{array}{l}\text { Quem é Beta? (1973) de } \\
\text { Nelson Pereira dos Santos }\end{array}$ & $8 / 9$ & $2 / 22$ \\
\hline $\begin{array}{c}\text { A Noite do Espantalho (1974) } \\
\text { de Sérgio Ricardo }\end{array}$ & $9 / 19$ & $6 / 26$ \\
\hline $\begin{array}{l}\text { Parada } 88 \text { - O Limite de Alerta } \\
\text { (1977) de José de Anchieta }\end{array}$ & $7 / 21$ & $10 / 34$ \\
\hline $\begin{array}{c}\text { Excitação (1977) de Jean } \\
\text { Garret }\end{array}$ & $4 / 4$ & $1 / 8$ \\
\hline $\begin{array}{c}\text { As Filhas do Fogo (1978) de } \\
\text { Jean Garret }\end{array}$ & $7 / 3$ & 4/19 \\
\hline $\begin{array}{l}\text { Fruto do Amor (1980) de } \\
\text { Milton Alencar Jr. }\end{array}$ & $11 / 16$ & $3 / 29$ \\
\hline $\begin{array}{c}\text { O Inseto do Amor: Anophelis } \\
\text { Sexualis (1980) de Fauzi } \\
\text { Mansur }\end{array}$ & $37 / 36$ & $2 * / 23$ \\
\hline $\begin{array}{l}\text { Abrigo Nuclear (1981) de } \\
\text { Roberto Pires }\end{array}$ & $6 / 10$ & $1 / 12$ \\
\hline $\begin{array}{l}\text { Punk's - Os Filhos da Noite } \\
\text { (1982) de Levy Salgado }\end{array}$ & $7 * / 17$ & $2 / 11^{*}$ \\
\hline
\end{tabular}




\begin{tabular}{|c|c|c|}
\hline $\begin{array}{l}\text { As Ninfetas do Sexo Selvagem } \\
\text { (1983) de Wilson Silva e lzat } \\
\text { Surman }\end{array}$ & $6 / 3$ & $0 / 17$ \\
\hline $\begin{array}{l}\text { A Mulher de Proveta (1984) de } \\
\text { José Rady }\end{array}$ & $6 / 2$ & $1 / 7$ \\
\hline $\begin{array}{c}\text { Amor Voraz (1984) de Walter } \\
\text { Hugo Khouri }\end{array}$ & $6 / 4$ & $4 / 28$ \\
\hline $\begin{array}{l}\text { A Quinta Dimensão do Sexo } \\
\text { (1984) de José Mojica Marins }\end{array}$ & $4 / 9$ & $2 / 8$ \\
\hline $\begin{array}{c}\text { As Sete Vampiras (1984) de } \\
\text { Ivan Cardoso }\end{array}$ & $21 / 16$ & $10 / 40$ \\
\hline $\begin{array}{l}\text { Areias Escaldantes (1985) de } \\
\text { Francisco de Paula }\end{array}$ & $23 / 44$ & $13 / 41^{*}$ \\
\hline $\begin{array}{c}\text { Por Incrível Que Pareça (1986) } \\
\text { de Uberto Molo }\end{array}$ & $6 / 21$ & $14 / 44^{*}$ \\
\hline $\begin{array}{l}\text { Oceano Atlantis (1991) de } \\
\text { Francisco de Paula }\end{array}$ & $10 * / 14$ & $15 / 39 *$ \\
\hline $\begin{array}{l}\text { O Monstro Legume do Espaco } \\
\text { (1995) de Petter Baiestorf }\end{array}$ & $4 / 23$ & $2 / 9$ \\
\hline Kenoma (1998) de Eliane Caffé & $9 / 35$ & $15 / 41$ \\
\hline $\begin{array}{c}\text { Acquaria (2003) de Flávia } \\
\text { Moraes }\end{array}$ & $8 / 29$ & $15 / 69$ \\
\hline $\begin{array}{c}\text { Um Lobisomem na Amazônia } \\
\text { (2005) de Ivan Cardoso }\end{array}$ & $7 / 12$ & $16 / 64$ \\
\hline $\begin{array}{c}\text { Centopeia (2005) de Daniell } \\
\text { Abrew }\end{array}$ & $3 / 4$ & $1 / 3$ \\
\hline $\begin{array}{l}\text { O Homem do Futuro (2011) de } \\
\text { Cláudio Torres }\end{array}$ & $5 / 21$ & $32 / 53$ \\
\hline $\begin{array}{l}\text { Área Q (2011) de Gerson } \\
\text { Sanginitto }\end{array}$ & $5 / 9$ & $9 / 24^{*}$ \\
\hline $\begin{array}{c}\text { Branco Sai, Preto Fica (2014) } \\
\text { de Adirley Queirós }\end{array}$ & $1 / 4$ & $1 / 7$ \\
\hline $\begin{array}{l}\text { Deserto Azul (2014) de Eder } \\
\text { Santos }\end{array}$ & $2 / 4$ & $4 / 21$ \\
\hline $\begin{array}{c}\text { A Repartição do Tempo (2016) } \\
\text { de Santiago Dellape }\end{array}$ & $5 / 7$ & $0 / 4$ \\
\hline
\end{tabular}

Tabela 1 - Mulheres no cinema brasileiro de FC4

4 Esta tabela mostra um primeiro levantamento sobre a quantidade de mulheres e homens no elenco e na equipe técnica em 36 filmes de ficção científica brasileiros. 0 símbolo (*) significa que pode haver alguma diferença nesses números, já que, alguns nomes não foram possíveis de identificar e checar a quem exatamente pertenciam. 
Nessa breve contabilização, constatamos que dentro deste recorte, apenas cinco filmes superaram a quantidade de mulheres no elenco: As ninfetas do sexo selvagem, $O$ inseto do amor, $A$ mulher de proveta - produções com teor erótico -, Amor voraz um filme com preocupações mais existenciais e que gira em torno da relação entre diversas mulheres e um homem misterioso e As sete vampiras - uma produção que envolve um cientista, crimes inexplicáveis e vampiros. Já no quesito mulheres em funções técnicas, o levantamento demonstra que as diferenças são ainda mais alarmantes, quase nunca se equilibrando e, em pelo menos seis produções das 36 identificadas, não houve a participação de nenhuma mulher na equipe técnica.

No âmbito dos curtas-metragens, a presença feminina parece ocupar um terreno um pouco mais amplo, principalmente em produções contemporâneas e direcionadas ao circuito dos festivais. Encontramos exemplo recentes na Mostra Brasil Distópico realizada na Caixa Cultural no Rio de Janeiro entre 15 e 27 de agosto de 2017: dos 21 curtas-metragens exibidos, pelos menos 9 obtiveram alguma direção feminina, tais como, Antes da encanteria (2016) de Gabriela Pessoa, Lívia de Paiva, Elena Meirelles, Jorge Polo e Paulo Victor Soares, Aiyé 3016 (2016) de Cine Translesbixa, Cat effect (2013) de Melissa Dullius e Gustavo Jahn, Hiperselva (2014) de Helena Lessa, Jorge Polo, Lucas Andrade e Pedro Lessa, Kbela (2015) de Yasmin Thayná, Os anos 3000 eram feitos de lixo ou (quando a dignidade da raça humana se afogou no chorume estático da arte da hipocrisia) (2016) de Cleyton Xavier, Clara Chroma, Ana All, Luana Rosa, Eduardo Sa Cin e Ana Elisa Alves, Solon (2016) de Clarissa Campolina, Triangulum (2008) de Melissa Dullius e Gustavo Jahn e X-Manas 
(2007) de Clarissa Ribeiro. Já na Mostra Sci-fi Brasil - Eles estão entre nós!, realizada pela Caixa Cultural no Rio de Janeiro entre $4 \mathrm{e}$ 16 de setembro de 2018, dos 12 curtas-metragens apresentados, 4 obtiveram alguma direção feminina, dentre eles, Tempo Real (2005) de Mino Barros e Joana Limaverde, Barbosa (1988) de Jorge Furtado e Ana Luisa Azevedo, Personal Vivator (2014) de Sabrina Fidalgo e $O$ Quebra-Cabeça de Tarik (2015) de Maria Leite.

Das abordagens utilizadas nos curtas-metragens, destacamos: os corpos queer no sertão do Ceará, os planos para derrubar a supremacia branca, os alienígenas que prometem eliminar a doença, a pobreza e os projetos monumentais, a experiência do racismo vivida por mulheres negras, a libertação da escravidão humana e ciborgues marginalizados, um corpo de aspecto humanoide e feminino como a gênese da vida, as figuras enigmáticas femininas que transportam pessoas, o submundo de bichas bandidas, travestis, sapatonas e corpos marginalizados, o tempo e a viagem no tempo, um extraterrestre documentarista que estudará o comportamento humano e, finalmente, um corpo velho substituído pelas máquinas.

Assim, com temáticas que percorrem, principalmente, as questões delegadas ao corpo, salientamos que a questão de gênero na diegese é tão presente quanto o minguado número de mulheres em cargos como: diretoras, roteiristas, produtoras, técnicas ou montadoras. Como bem aponta Loreley Garcia em Meio Ambiente \& Gênero (2012), livro que trata do ecofeminismo como um movimento que revela a importância da participação feminina no manejo dos ecossistemas, o desenvolvimento sustentável e a convivência harmoniosa - o gênero é uma construção que se encontra, também no próprio corpo. 
A diferença de gênero é outra estrutura, como a oposição natureza/cultura. As relações de gênero situam-se na franja fronteiriça entre a natureza e a cultura: no corpo. Na maior parte das culturas, essa dupla oposição apresenta o corpo como metáfora, expressa dúvidas existenciais sobre a natureza e a cultura, uma vez que é natureza formatada pela cultura. $(2012$, p.70)

O raciocínio binário do qual a autora se refere, também implica em discursos construídos em uma lógica de dominação que devem, como questiona Judith Butler (2003), desmantelar as estruturas que os fortalecem e, principalmente, rejeitar a categoria "mulheres", por exemplo, como os únicos sujeitos do feminismo. Assim, se as afinidades mulher-natureza como percebidas no Ocidente carecem de abordagens mais transculturais que as percepções do inconsciente humano, o cinema como discurso de sua sociedade também se esculpe em meio às mesmas condições sócio históricas, no entanto, tal formato não elimina as pequenas subversões.

\section{AUTORIA FEMININA E ARTE FEMINISTA}

Em Explosão feminista: Arte, cultura, política e universidade (2018), livro organizado por Heloísa Buarque de Hollanda, um dos artigos voltados para a discussão acerca da arte feminista escrito por Duda Kuhnert, demonstra um posicionamento extremamente norteador para esclarecer ideias comumente associadas às artistas das mais variadas vertentes: o fato de se ter algo produzido por uma mulher, não significa que se trata de uma obra feminista. Ao nos preocuparmos muito mais com quem ocupa determinados espaços, a problemática da autoria é determinada por uma série de questões sobre as quais conseguimos resguardar comparativos 
com a própria transformação do feminismo. Principalmente no Brasil, a história das mulheres é, como aponta Céli Regina J. Pinto, um movimento de natureza bastante fragmentada.

O movimento feminista, em países como o Brasil, não pode escapar dessa dupla face do problema: por um lado, se organiza a partir do reconhecimento de que ser mulher, tanto no espaço público como no privado, acarreta consequências definitivas para a vida e que, portanto, há uma luta específica, a da transformação das relações de gênero. Por outro lado, há uma consciência muito clara por parte de grupos organizados de que existe no Brasil uma grande questão: a fome, a miséria, enfim, a desigualdade social, e que este não é um problema que pode ficar fora de qualquer luta específica. (2003, p.45)

Nesse sentido, assim como não podemos falar de um único feminismo representativo de todas as mulheres, também não é possível determinar padrões que consigam, de fato, definir a ficção científica brasileira. O dito terreno desabitado, não significa, necessariamente, infértil, mas sim um terreno que ainda não foi contado nas histórias ou, não foi identificado nas histórias já contadas.

Com duração de 103 minutos, Acquaria se passa em um futuro distante onde o planeta se encontra em ruínas. A escassez de água devido às agressões constantes à natureza é o mais grave dos problemas, apenas pequenas comunidades de pessoas foram capazes de sobreviver. Há 15 anos um casal de cientistas, Bártok (Alexandre Borges) e Nara (Júlia Lemmertz) habitavam uma vila, local em que trabalhavam no desenvolvimento de uma máquina geradora de água. A vila era muito conhecida entre viajantes e 
músicos, já que Bártok também construía instrumentos musicais. Após serem pegos por um grupo perigoso de nômades mutantes, o casal foi morto e a vila destruída. Atualmente, Kim (Junior Lima) - o filho do casal - Guili (Igor Rudolf) e Gaspar (Emílio Orciollo Neto) vivem no que restou deste local, juntos de seu fiel cachorro. Sarah (Sandy Leah), uma guerreira misteriosa e cheia de habilidades, é encontrada no meio do deserto por Kim. Mesmo desconfiados, os três decidem ajudá-la concedendo-lhe um lugar para ficar, o que dá início a uma série de esclarecimentos familiares sobre os assuntos inacabados do passado.

Com uma temática voltada para as questões ambientais e suas consequências como resultado de nossa agência irresponsável no planeta e seus recursos naturais, Acquaria ao mesmo tempo em que recupera uma corrente mais depurada e com intenções de problematizar temáticas ambientais e ecológicas vistas em filmes como Parada 88 - Limite de alerta (1977) de José de Anchieta e Abrigo Nuclear (1981) de Roberto Pires, aponta para uma comparação com o filme Roberto Carlos em Ritmo de aventura (1968), um musical nonsense que justifica a FC através dos vilões que pretendem reproduzir um cérebro eletrônico do cantor para ganhar dinheiro. A crítica à cultura de massa no filme de Roberto Farias especula enquanto material extradiegético em Acquaria os protagonistas são também, ícones da música pop-sertaneja - o que faz da produção, em muitos momentos, estar subordinada à estética de um videoclipe.

Já no filme Kenoma a história acontece em um distante povoado rural onde vivem garimpeiros e pequenos comerciantes. Logo no início, Jonas (Enrique Díaz) é atraído pela jovem Tari 
(Mariana Lima), que em sua bicicleta o leva para a cidade, local em que o modo de vida ainda acontece de forma muito primitiva. Jonas conhece Lineu (José Dumont), um habitante obcecado pela criação de uma máquina capaz de produzir o moto-perpétuo, ou seja, uma máquina que movimenta o velho moinho abandonado sem a necessidade de um combustível. Há mais de 20 anos, Lineu converteu sua existência nesta missão cheia de fracassos e, ao mesmo tempo em que ele desafia as leis da física, também vai contra os anseios do poderoso Gerônimo (Jonas Bloch), o dono do moinho e o maior proprietário de terras da região. Gerônimo é pragmático e possui interesses econômicos, Lineu é um sonhador. Nesse sentido, Jonas alia-se ao pseudo-cientista mais pela sua determinação que pelo seu invento, que, aos olhos de Gerônimo só consome tempo e energia. Enquanto isso, o relacionamento entre Tari e Jonas só cresce, a garota funciona como um tipo de alicerce para as estruturas abaladas do povoado, o amor cresce ao mesmo tempo em que a busca pela realização de um sonho da humanidade dá sinais de alguma concretização.

Diferente de Acquaria, que fora um dos cinco filmes brasileiros dirigidos por mulheres que renderam mais bilheteria entre os anos de 2002 e $2012^{5}$ e que obteve renda de $\mathrm{R} \$ 4.466 .393,00$, com 837.695 de público, Kenoma foi uma produção que, como afirma a diretora, reverbera a importância e as problemáticas da distribuição e da exibição no cinema brasileiro, já que o filme fora lançado com apenas três cópias.

5 Os outros quatro filmes são Xuxa e o Mistério da Feiurinha (2009) de Tizuka Yamazaki, Ó Pai Ó (2007) de Monique Gardemberg, Desenrola (2011) de Rosane Svartman e As Melhores Coisas do Mundo (2010) de Laís Bodansky. Essas informações foram retiradas do artigo intitulado Problematizando gêneros: um olhar sobre o cinema brasileiro em busca de resistência ao patriarcado (2015) de Aline Anacleto e Fernando Teixeira-Filho. 
É uma loucura! São R\$1,7 milhões investidos num filme; eu passo três, quatro anos trabalhando, e o filme é lançado com três cópias num território enorme como o do Brasil. É quase como enterrá-lo num cemitério! E isso é uma contradição. (NAGIB, 2002, p.136)

Nesse caso, o filme per se já se configura em uma problemática que atravessa questões sociais e culturais ainda mais abrangentes e que se inserem, por meio da própria história, em um mundo aparentemente distante do nosso contemporâneo, mas ao mesmo tempo tão próximo do povo brasileiro, revelando, como bem apontado anteriormente por Céli Regina J. Pinto (2003), o quanto as lutas configuram-se de forma fragmentada e complexa. Somos, nesse sentido, mais que uma - somos muitas.

A ideia de Kenoma surgiu do desejo de conhecer o universo daqueles personagens que vivem à margem do mundo moderno. A busca por esse homem ainda não tão intermediado pelas novas tecnologias vinha da suposição, talvez ingênua, de descobri-lo mais próximo dos valores essenciais da vida. Encontrar essa realidade pressupunha sair dos limites dos grandes centros urbanos e fazer uma expedição às pequenas comunidades ou povoados que sobrevivem em boa parte do território brasileiro. (CAFFÉ; SVARTMAN, 1998, p.192)

Em uma abordagem quase antropológica, o filme de Caffé trabalha em uma zona limítrofe do gênero da FC e do naturalismorealismo, atravessando uma correlação terceiro-mundista e com grande economia de recursos, bastante diferente da produção com caráter de pós-retomada e que abusa da computação gráfica, 
como é Acquaria. Em duas produções separadas por um intervalo de 5 anos, encontramos ressonâncias em histórias que dialogam não apenas pelo dado da direção feita por mulheres, mas em uma abordagem que, em alguma medida esmera o que Carol Gilligan (1982) expressa por meio de uma ética das relações e das responsabilidades, ou seja, as escolhas estão muito mais ligadas a percepção dos sujeitos como seres independentes que, por exemplo, a sapiência dos indivíduos autônomos.

\section{FC EM UMA PERSPECTIVA FEMINISTA}

Com base nos pensamentos de Nancy Chodorow (1978) que acredita que as meninas formam o senso de si e a subjetividade na relação com a mãe, adquirindo qualidades de conexão e dependência, o que possibilita e explica - culturalmente e não biologicamente - a criação de um eu mais vinculado aos outros, destacamos uma espécie de espírito coletivo recorrente nas histórias de autoria feminina. Como as temáticas já apontadas reverberam, as questões em ambos os longas interpelam valores de um desenvolvimento baseado ou na devastação - como em Acquaria com a falta de água - ou no atraso - como em Kenoma, que sobrevive de formas antiquadas e aponta para a tecnologia em sua ideia mais aloucada.

No Brasil, a conjunção entre ecologia e feminismo ocorre tardiamente e quase sempre em conjunto com demandas de direitos econômicos e sociais, o que desemboca, por exemplo, em críticas direcionadas ao neoliberalismo, seus impactos negativos e os retrocessos no quesito dos serviços estatais para as mulheres. No cinema, os filmes de Eliane Caffé e Flávia 
Moraes constroem-se em uma narrativa que se aproveita dessa conjuntura e traz, principalmente para as personagens femininas, uma construção profundamente complexa, ancorada em permanências e transformações para a figura feminina no cinema brasileiro.

Em Kenoma a única personagem feminina é Tari, que se configura como um tipo de mediadora dos relacionamentos conturbados entre Lineu, Gerônimo e Jonas. Ao levar Jonas, o homem por quem vai se apaixonar, para a cidadezinha, Tari conduz a bicicleta já velha por um terreno que ela parece conhecer muito bem. A atenção que concede ao aparente lunático Lineu, repete não apenas o seu papel como cuidadora, mas a sensibilidade em compreender o que para ele é importante: a efetivação de sua invenção.

Tari não constrói nada, mas é capaz de apoiar à sua maneira o seu mais novo amor e o velho Lineu. Na realidade, ela e o inventor possuem uma relação inconstante, são próximos e distantes ao mesmo tempo. Tari conforta o corpo, segura, carrega e cuida dos machucados físicos de Lineu, mas diz para o velho que as pessoas têm que ir embora algum dia: uma exacerbação da sua própria experiência com a mulher que parece ser sua mãe (Eliana Carneiro) e que fora embora. Paciente e bondosa, Tari é o modelo daquilo que se espera de uma jovem recatada e inserida no modelo patriarcal e de progresso incessante. A jovem passa grande parte do tempo em um tipo de escola, onde ensina crianças, adultos e idosos a escrever, realiza trabalhos manuais costura, cozinha e tingimento; cuida dos machucados de Pedro (Matheus Nachtergaele) quando ele é agredido pelos capangas de 
Gerônimo em ameaça ao inventor. Em meio a dor e o sofrimento, ela diz que ele vai ficar bom, Pedro a espia nua, ela também é a paixão do jovem garoto, uma paixão não correspondida, ou seja, um corpo inalcançável para Pedro.

Ao mesmo tempo, Tari é uma personagem que está além daquilo que a cidade de Kenoma pode oferecer: quando Jonas propõe que eles fujam, o argumento é, justamente, oferecer um mundo maior que o que ela conhece, "sei que você imagina que trago muitas história do mundo, mas não trago nenhuma experiência, como faço pra você ficar comigo?", Ihe pergunta Jonas. Tari não age no ímpeto, é racional e está o tempo todo em movimento para sobreviver. $\mathrm{Na}$ contramão, sua bicicleta agora é conduzida por Jonas, o casal perambula pela noite, quando uma tempestade que atrapalha Lineu a faz interromper o encontro para ajudá-lo - Tari está sempre pensando nos outros e não nela mesma: um vestígio de mulher submissa ou um indício de uma mulher solidária?

Longe de progredir, pelo menos economicamente, a cidade de Kenoma vive estática e dependente de Gerônimo - não existe chance para o coletivo, ou seja, o bem maior; sua fissura é pelo progresso e não pelas pessoas. Se pensarmos na própria simbologia daquilo que o inventor pretende colocar em prática, mesmo que altruísta, a ânsia pelo maquinário bem-sucedido já não é mais para o povo, e sim para preencher uma lacuna de realização pessoal e paranoica de Lineu, um claro exemplo da lógica linear e progressista que dá forças às fraquezas de nosso próprio mundo.

Dessa perspectiva, entrever a figura de Tari como um ponto fora da curva, também se torna um desafio possível para interpretarmos 
de forma distinta da esperada: uma figura feminina que não é protagonista, que está em grande parte das cenas sozinha, que serve como alicerce para seus conhecidos e que espera pelo amor heterossexual. Todas essas recusas são as mais comuns análises para Tari, todavia, inserida dentro de uma corrente como a exposta pelo ecofeminismo que "se propõe a desestabilizar as bases sobre a civilização que separa natureza/cultura e hierarquiza os sexos" (GARCIA, 2012, p.74), ela não é a única. As entrelinhas do discurso são visualizadas de forma distinta: a circularidade como uma metáfora da regeneração e do cuidado, o que, muitas vezes, passa despercebido pela lógica produtiva linear e até mesmo paternalista.

A relação com a figura materna, da qual Tari carrega a fotografia de um retrato que, como ela mesma diz, não pode ser compartilhado com ninguém, é a mesma mulher que lhe oferece colo anteriormente e a abandona, deixando-a sozinha, assim como Tari faz no futuro próximo. A fuga da menina que acontece mais tarde, momento em que prevemos ou esperamos a companhia de Jonas, é quebrada por uma jovem que vai embora sim, mas sozinha - ou seja, uma réplica de sua mãe.

Ocorre que a mãe como Outro é essencial na formação do homem, mas na formação da mulher se baseia numa contínua identidade com a mãe, que não aparece como um Outro para ela. (GARCIA, 2012, p.94)

Ainda que tal afirmação ocorra dentro de um terreno formatado por polaridades - feminino-masculino - o aparato conceitual que identifica o homem monopolizador dos sistemas simbólicos e a mulher no domínio da natureza, também perfaz um discurso 
cultural que acaba por validar determinados pensamentos. Ao transportarmos os atributos arbitrários provindos da leitura que a cultura faz da natureza, os antagonismos entre mulheres e homens são construções que, no mais, precisam ser desconstruídas, assim como a própria ideia de uma mulher submissa ou cuidadora ser, respectivamente, ligada a aspectos do feminino. Tari reproduz o que a possível mãe desperta, escapulir de um mundo onde a circularidade que ela é ainda não se sustenta - a máquina de movimento perpétuo simboliza isso, denomina a circularidade feminina que não é necessariamente uma prisão, mas exatamente a transformação daquilo que precisa ser pensado em contraponto a linearidade masculina egoísta.

No caso do filme Acquaria a apresentação de estereótipos de gênero e papéis demarcados também é presente, mas não é o único caminho a ser desbravado. A personagem de Sarah é uma mulher guerreira que possui características capazes de questionar a visão tradicional de mulher. Ao perambular sozinha pelo deserto, Sarah torna-se uma exímia caçadora - até mesmo mais experiente que seu irmão, Kim. A função da caça que até o momento era desempenhada pelo desajeitado jovem, passa a ser uma das tarefas de Sarah quando ela habita a nova casa. Além disso, ela executa atividades como ensinar Guily a jogar o bumerangue, defende a casa matando animais perigosos e fabrica um objeto em solda como presente para Guily após o acidente que desmaterializada o cachorro da família.

Um tanto misteriosa e de pouca conversa, a jovem não é muito bem vista por Gaspar, o que mais tarde despertará um amor que não será consolidado. A implicância com Sarah é o que dá 
o clássico tom do romance: assim como na cena em que Tari de Kenoma é admirada por Pedro, o mesmo acontece com Sarah que, no meio de seu banho também é observada nua por Gaspar - o seu corpo desbravador do deserto, agora é desbravado pelo olhar masculino, uma inversão que não faz de Sarah somente um objeto de admiração, mas adiciona uma outra camada a complexidade de seu corpo, esse esmo que é interpretado pela cultura.

Desde o início do filme, os papéis se estabelecem dentro da própria estrutura familiar: o pai como um inventor e a mãe como a figura cuidadora que produz o alimento, confirmam alguns dos estereótipos ligados ao suposto papel da maternidade. O que é importante destacar na história de Sarah, nesse sentido, não é exatamente a sua relação com a mãe - que já morre logo no início do filme - mas a relação que se determina entre a garota e o seu pai adotivo Ábaddon (Daniel Ribeiro), o líder dos saqueadores de água, que são conhecidos pela destruição que imperam na cidade.

Tal relação é desenhada de uma forma, talvez, muito mais complexificada que a da própria família de sangue, afinal, Sarah enxerga em Ábaddon a real figura de um pai e a sua vilania não chega a atrapalhar o amor entre eles. Em uma das cenas finais, quando descobre que Ábaddon fora responsável pela morte de sua família de sangue, Sarah hesita, afinal, ela precisa abrir mão da relação que construiu por toda uma vida: Ábaddon morre porque ela decide deixá-lo morrer por um bem maior.

O papel de uma guerreira independente começa a se modificar, justamente depois da criação do laço afetivo com o seu irmão de sangue e o laço amoroso com Gaspar. Sarah torna-se mais sensível 
e vulnerável, assumindo as determinantes culturais e ocidentais do papel da mulher: o amor heterossexual a modifica. Esse mesmo amor chega a funcionar como um tipo de libertação - em uma das caixas de história que são adquiridas por meio de Zavos (Milton Gonçalves), um homem responsável por guardar as histórias do mundo em caixinhas, a lenda de Acquaria é revelada: a mulher liberta o príncipe congelado da cidade por meio da música, ou seja, por meio de sua própria voz.

Assim, o grande instrumento de libertação de Sarah é descobrir que a sua voz é a forma de ativar a máquina - já concebida há muitos anos pelo seu pai, Bártok - e que poderá salvar a todos, recuperando a água, que até então encontrava-se escassa. Acusada por Gaspar de pegar um cilindro de água - material extremamente raro - Sarah é encarada como uma forasteira perigosa, no entanto, o simbolismo replicado na volta da água por conta da máquina que é ativada por sua voz, alude à figura de Sarah como um tipo de salvação do coletivo, afinal, a água potável é finalmente trazida por ela. Aqui se repete a ligação entre a mulher e a natureza, todavia, suas ações acentuam um aspecto solidário que rebate na ideia da circularidade, da regeneração e, principalmente, do lugar que habitamos e dividimos com o outro.

\section{BREVES CONSIDERAÇÕES}

Ao nos voltarmos para a produção cinematográfica de ficção científica brasileira com ênfase na autoria feminina, salientamos uma dificuldade já identificada nas mais diversas correntes artísticas e na própria história: a ausência, a invisibilidade e, principalmente, o encobrimento daquilo que chamamos de feminino. Dizer que 
não existimos ou não fizemos algo, é também um discurso que confere ainda mais desvalorização à história da mulher. Talvez, esses mesmos discursos estejam encobertos, sejam subversivos, pequeninos e sutis, afinal, tudo aquilo que é grandioso faz parte de uma lógica linear que sempre nos negou.

Afirmar que existem temáticas estabelecidas para um filme quando ele é dirigido por uma mulher, é repetir um essencialismo do qual necessitamos fugir cada vez mais. Todavia, identificar assuntos que de alguma maneira incorporam as pautas femininas é detectar um viés possível de abordagem. Em Kenoma e Acquaria lidamos com histórias que detectam pautas das relações em coletivo e essas, quase sempre ligadas as figuras femininas: a preocupação de Tari com aqueles que estão a sua volta ou a contribuição de Sarah para que a água volte a habitar o seu planeta.

Descrevemos personagens que, em sua maioria, dividem os protagonismos, abrem mão de certas decisões pessoais e são admiradas/ameaçadas pelos seus corpos, todavia, ao tratarmos de tramas que pretendem descrever o nosso tempo, quais as perspectivas para a liderança única em um mundo onde as grandes lideranças tornam-se ultrapassadas? De que nos serve o individualismo em um mundo onde cada vez mais lutamos pela erradicação do egoísmo, que é a base de grande parte de nossos problemas sociais, econômicos e também, culturais?

Ambas as histórias não discutem ou direcionam-se para a mulher, mas perfazem, de alguma maneira, uma visão que considera a circularidade, a coletividade e a sociedade, ou seja, uma lógica que metaforiza o feminino. Kenoma apresenta um mundo 
tão primitivo quanto o nosso, a regeneração está na fuga de Tari que entende o seu papel - suas ações são dirigidas sempre aos outros, mas os outros ainda vivem sobre as regras de um mundo produtivo e, no mais, destrutivo. Em Acquaria a figura guerreira e solitária de Sarah é interrompida pela família e pelo amor, no entanto, ao descobrir-se como uma peça chave para reverter a sequidão de seu mundo, a jovem exprime a salvação através da própria natureza com o retorno da água: o mundo escasso que se vive é o resultado de uma mão progressista e individualista. Nesse sentido, ambas as autorias revelam um terreno que, mesmo pouco explorado e timidamente discutido, insiste em sobreviver, e é desse resquício que efetivamente sobreviveremos enquanto humanidade e cinematografia.

\section{REFERÊNCIAS}

ANACLETO, Aline Ariana Alcântara; FILHO, Fernando Silva Teixeira (2015). "Problematizando gêneros: um olhar sobre o cinema brasileiro em busca de resistência ao patriarcado". Revista Ágora, (22), Espírito Santo, 136-157. In http://periodicos.ufes.br/agora/article/view/13613 Acesso em 15.Mai.2019.

BUTLER, Judith (2003). Problemas de gênero: feminismo e subversão da identidade. Rio de Janeiro: Civilização Brasileira.

CAFFÉ, Eliane; SVARTMAN, Rosane (1998). "O artesão, Alice, a máquina e o espelho". Cinemais, (11), Mai./Jun., 192.

CHODOROW, Nancy (1978). The Reproduction of Mothering: Psychoanalysis and the Sociology of Gender. Berkeley: UC Press.

GARCIA, Loreley (2012). Meio ambiente \& gênero. São Paulo: Editora Senac São Paulo.

GILLIGAN, Carol (1982). In a Different Voice. Cambridge: Harvard University Press. HOLLANDA, Heloísa Buarque de (2018). Explosão feminista: Arte, cultura, política e universidade. São Paulo: Companhia das Letras. 
LE GUIN, Ursula K. (2014). A mão esquerda da escuridão. 2.ed. São Paulo: Aleph. NAGIB, Lúcia (2002). O cinema da retomada: depoimentos de 90 cineastas dos anos 90. São Paulo: Ed. 34.

PINTO, Céli Regina J. (2003). Uma história do feminismo no Brasil. São Paulo: Fundação Perseu Abramo.

SHOHAT, Ella; STAM, Robert (2006). Crítica da imagem eurocêntrica Multiculturalismo e Representação. São Paulo: Cosac Naify. 